Universidade Tecnológica Federal do Paraná - UTFPR

Campus Ponta Grossa - Paraná - Brasil

ISSN: 1981-3686 / v. 2-, n. 1 : p. 115-122, 2008
Revista Brasileira de Tecnologia

Agroindustrial

\title{
OTIMIZAÇÃO DO PROCESSO DE EXTRAÇÃO AQUOSA DE INULINA DE CHICÓRIA.
}

\section{OPTIMIZATION OF THE AQUEOUS EXTRACTION OF INULIN FROM CHICORY ROOTS}

\author{
Vanessa Panasco da Silva ${ }^{1}$; Sonia Couri ${ }^{2}$; Flávia S. Gomes ${ }^{2}$, Regina Isabel Nogueira ${ }^{2}$, Suely Pereira Freitas ${ }^{1}$ \\ ${ }^{1}$ Universidade Federal do Rio de Janeiro- UFRJ - Rio de Janeiro - Brasil, \\ ${ }^{2}$ Embrapa Agroindústria de Alimentos - CTAA- Rio de Janeiro - Brasil, scoury@ctaa.embrapa.br
}

\begin{abstract}
Resumo
Neste trabalho, o processo de extração sólido-líquido, usando a água quente como solvente, foi otimizado para obtenção de um extrato concentrado de inulina a partir da raiz de chicória desidratada. Na primeira parte deste trabalho, foram estudados os efeitos simultâneos da temperatura e razão água/substrato $(p / p)$ no rendimento do processo. Os dados experimentais foram gerados a partir de um planejamento composto central e analisados pela técnica de superfície de resposta. O teor de inulina no extrato seco foi determinado por cromatografia líquida de alta eficiência (CLAE). Pode-se concluir que o rendimento de extração apresentou uma correlação positiva com o aumento da razão solvente/substrato $(p=0,002)$ mas não foi influenciado pelo aumento da temperatura $(p=0,3416)$ na faixa analisada $\left(70\right.$ a $\left.90^{\circ} \mathrm{C}\right)$. Nas diferentes condições do planejamento experimental, as análises indicaram um teor de sólidos entre $5 \%$ e $10 \%$ no extrato aquoso e um teor de inulina máximo de $74 \pm 5 \%$, em base seca. De acordo com o estudo cinético de transferência de massa, a $70^{\circ} \mathrm{C}$, não se observou um aumento significativo no rendimento de extração, após 30 minutos de incubação. Visando aumentar, simultaneamente, o teor de soluto na fase aquosa e o teor de inulina no extrato seco, foram realizados novos experimentos mantendo-se a temperatura de incubação a $70^{\circ} \mathrm{C}$ e variando-se a concentração de substrato na mistura entre 10 e $50 \%$ (p/p). Na condição selecionada (25\% p/p substrato/água), obteve-se um extrato aquoso com cerca de $18 \%$ de soluto e um teor de inulina de $93 \pm 1 \%$, em base seca.
\end{abstract}

Palavras-chave: inulina, raiz de chicória, extração aquosa.

\section{Introdução}

A chicória (Cichorium intybus) é uma planta nativa da Europa que pode ser cultivada em praticamente todo o mundo. As variedades cultiváveis de chicória se adaptam bem ao clima temperado ou frio. No Brasil, podem ser plantadas durante o ano todo, porém desenvolvem-se melhor no inverno e são colhidas na primavera, época em que apresentam maior teor de inulina (ALZUGARAY \& ALZUGARAY, 1983). A inulina é uma glicofrutana de reserva presente nos tubérculos e pode ser encontrado em diferentes produtos vegetais dentre os quais destacam-se as raízes de chicória. Considerando suas propriedades funcionais, a inulina é indicada como 
ingrediente em uma série de alimentos formulados para dietas especiais. É utilizada na indústria alimentícia atuando como substituto do açúcar ou da gordura. Além disso, a inulina é utilizada como um ingrediente funcional na indústria alimentícia e farmacêutica (ROBERTFROID, 2001).

O processo convencional de extração da inulina é conduzido em meio aquoso a partir da amostra fresca. Este procedimento reduz o consumo de água, porém está restrito aos períodos da colheita. A raiz de chicória é um produto altamente perecível, exigindo, do ponto de vista industrial, um curto período de processamento. Portanto é necessário criar alternativas para disponibilizar a raiz de chicória ao longo do ano. A secagem é uma alternativa para diminuir a atividade de água da matéria-prima e, conseqüentemente, prolongar a sua vida útil (OLIVEIRA et al., 2006).

A solubilidade da inulina em água depende fortemente da temperatura, sendo fracamente solúvel a temperaturas baixas. De acordo com SILVA (1996), a $10^{\circ} \mathrm{C}$, a solubilidade é de $6 \%$, ao passo que, a $90^{\circ} \mathrm{C}$, cresce para aproximadamente $35 \%$.

No Brasil, ainda não existe produção comercial de inulina de chicória e há uma escassez de estudos nessa área, principalmente no que diz respeito ao escalonamento dos processos de extração, concentração e purificação (NOGUEIRA, 2002). Este trabalho teve como objetivo geral aperfeiçoar o processo de extração aquosa partir da raiz de chicória desidratada visando maximizar simultaneamente a concentração de soluto na solução e de inulina no extrato seco.

\section{Materiais e Métodos}

Matéria prima: A chicória da variedade Fredonia, previamente selecionada por FIGUEIRA (2000), foi plantada na Embrapa Agrobiologia - Seropédica/RJ, no outono, por se tratar do período de maior produtividade. A colheita foi realizada na primavera, antes da floração, pois esse é o período de maior concentração de inulina nas raízes. As raízes frescas foram lavadas, embaladas a vácuo e imediatamente armazenadas em câmaras frias a $20^{\circ} \mathrm{C}$ abaixo de zero.

Processamento: Corte e Secagem: Após descongelamento, as raízes foram cortadas em cubos de aproximadamente $5,0 \mathrm{~mm}$ e submetidas à secagem em um secador com fluxo de ar convectivo a $60^{\circ} \mathrm{C}$ e velocidade de $1 \mathrm{~m} / \mathrm{s}$. Os parâmetros de secagem foram previamente otimizados (COURI et al., 2005). A Figura 1 mostra detalhe da raiz de chicória fresca e da amostra fatiada e desidratada.

Figura 1 - Fotos da raiz de chicória fresca e da raiz de chicória desidratada
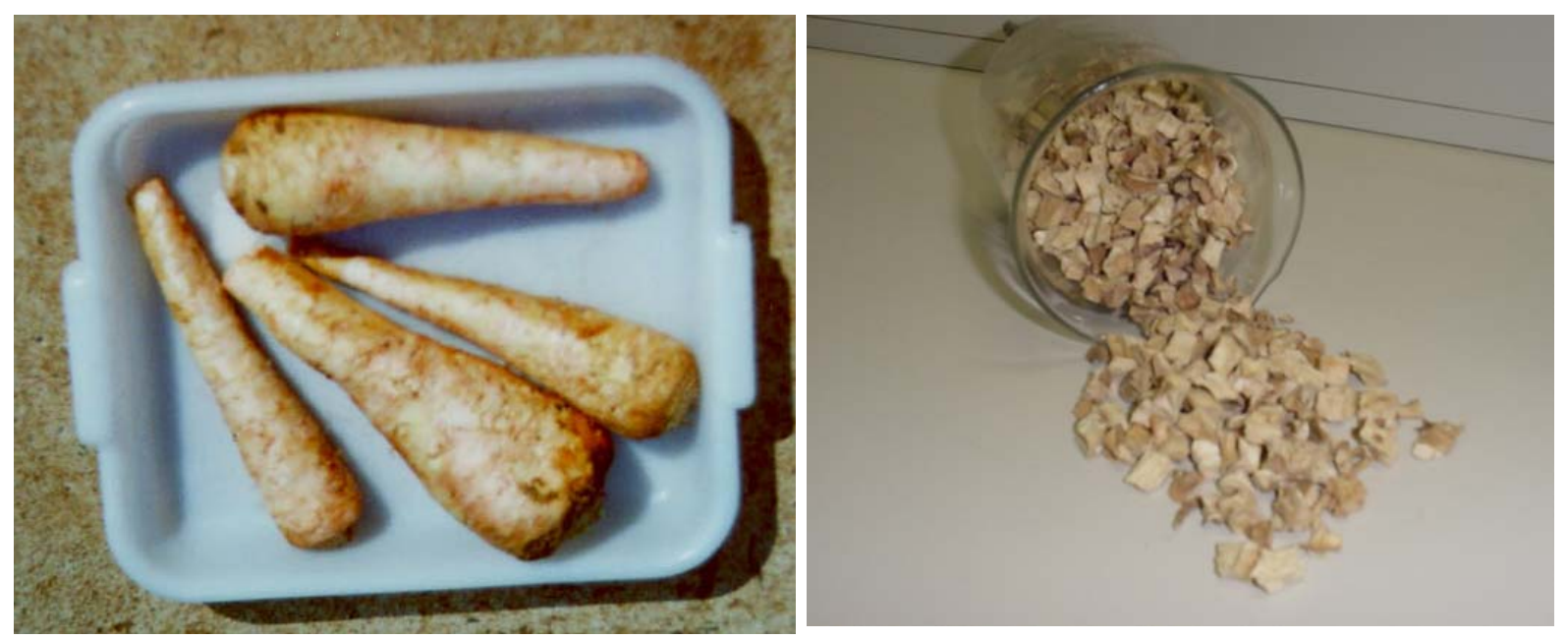

Extração 1: O processo de extração foi realizado em banho termostático com controle de agitação e temperatura, utilizando-se água como solvente. As variáveis independentes foram a temperatura da 
água e a razão entre a razão solvente/substrato (p/p). A agitação de 25 rpm foi selecionada de modo a se manter o material sólido em suspensão.

Filtração: O extrato obtido foi submetido à filtração sob vácuo usando papel de filtro de velocidade rápida para remoção de fibras e em seguida sob filtração lenta, com a finalidade de remover partículas dispersas no extrato. Verteu-se a solução aquosa para um becher previamente tarado e secou-se em estufa ventilada a $60^{\circ} \mathrm{C}$, para obtenção do extrato seco.

Extração 2: Novos experimentos foram realizados a $70^{\circ} \mathrm{C}$ para diferentes concentrações da amostra desidratada: 10, 20, 30, 40 e 50\% (p/p). Nesta etapa determinou-se o rendimento do processo (g de extrato seco/g de amostra), o teor de soluto no extrato aquoso (g de soluto/g de água), o teor de inulina no extrato e a fração de água retida na torta. O extrato filtrado e a torta retida no filtro foram colocados em estufa a $60^{\circ} \mathrm{C}$ até peso constante.

Experimentos em dois estágios. Para aumentar a eficiência de extração sem reduzir a concentração de inulina no extrato seco, o processo foi conduzido em dois estágios. Na primeira etapa a proporção solvente/substrato foi de 3:1 e no segundo estágio de 1:1, uma vez que a torta residual que deixa o estágio 1 retém $2 \mathrm{~g}$ de água/g de amostra seca.

\section{Análises Químicas:}

A composição centesimal da raiz de chicória foi determinada de acordo com a metodologia padrão da AOAC (2000).

As análises de concentração global de inulina no extrato seco foram realizadas através de cromatografia líquida de alta eficiência nas seguintes condições operacionais: coluna - Aminex HPX-87C (300 x 7.8 mm, d.i.); detetor de índice de refração modelo Waters 2414; eluente: água; vazão de $0,3 \mathrm{ml} / \mathrm{min}$; volume injetado de $20,0 \mathrm{ml}$; temperatura da coluna de $80^{\circ} \mathrm{C}$; temperatura do detetor de $40^{\circ} \mathrm{C}$.

Análise estatística: O rendimento de extração foi avaliado em função da temperatura e da razão solvente/carga. Os resultados experimentais, obtidos a partir do planejamento fatorial com ponto central (Tabela 1), foram analisados utilizando-se a metodologia de superfície de resposta (STATISTICA 7.0). As variáveis que apresentaram valor $\mathrm{p}<0,05$ foram consideradas significativas (BARROS NETO et al., 1996; BOX et al., 1978).

Tabela 1. Níveis analisados para os parâmetros do processo de extração da inulina de chicória em meio aquoso

\begin{tabular}{lccc}
\hline Parâmetros/Níveis & -1 & 0 & +1 \\
\hline Temperatura & 70 & 80 & 90 \\
Razão Água/Substrato & $4: 1$ & $5: 1$ & $6: 1$ \\
\hline
\end{tabular}

\section{Resultados}

A matéria prima in natura apresentou a seguinte composição centesimal: $1.08 \%$ de cinzas 78,4\% de umidade, 0,66\% de proteína, 0,39\% de óleo e 19,73\% de carboidratos totais. Estes resultados são similares àqueles disponíveis na literatura para a mesma variedade de chicória cultivada em Campinas (LEITE, 2005). Após secagem a umidade foi reduzida para 7,6 \pm 0,2.

A análise estatística dos efeitos indicou que a razão água/substrato é o parâmetro mais relevante no rendimento de extração da inulina $(\mathrm{p}<0,005$ e $\mathrm{F}=503,84)$ seguido do termo de segunda ordem em temperatura $(\mathrm{p}<0,05 ; \mathrm{F}=57,44)$ (Figura 2$)$.

O processo de extração aquosa da inulina de chicória, a partir da raiz desidratada, forneceu 
rendimentos elevados para temperaturas entre 70 e 90C e razão água substrato entre 4:1 e 6:1 (Figura 3). O cromatograma (Figura 4) indicou um pico nítido de inulina no tempo de retenção de 14 minutos. O teor de inulina no extrato, determinado por HPLC, foi cerca de $74 \pm 5 \%$ o que correspondeu a um rendimento de cerca de $38 \pm 2$ g de inulina por 100 g. de amostra, em base seca.

Figura 2. Gráfico de pareto para análise de efeitos no processo de extração aquosa de inulina de chicória. 1- temperatura; 2 - razão água/substrato

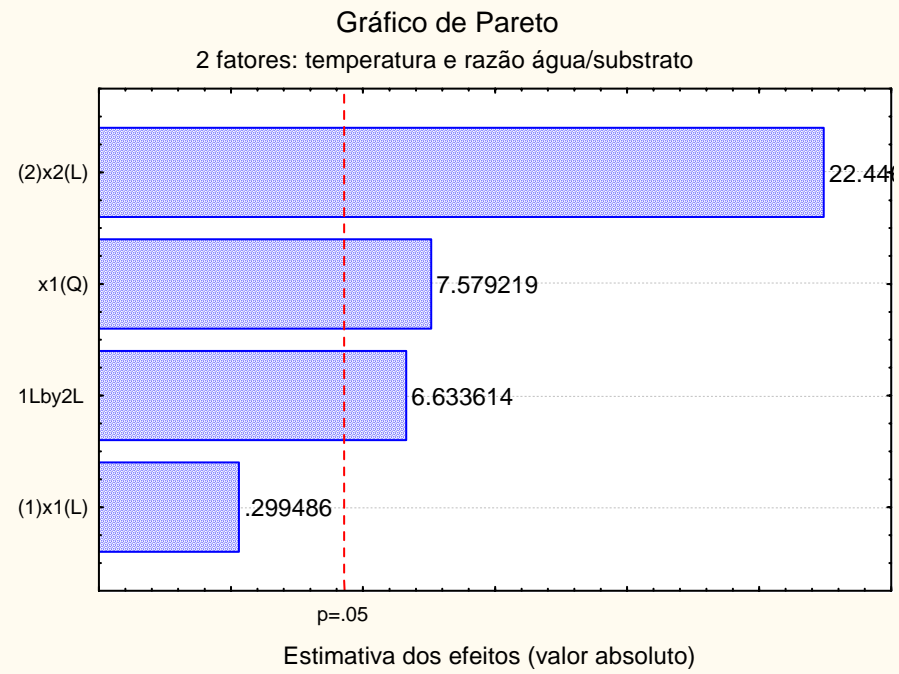

Figura 3. Superfície de resposta para o processo de extração aquosa de inulina de chicória

Superfície de resposta

2 fatores: Temperatura e Razão água/substrato

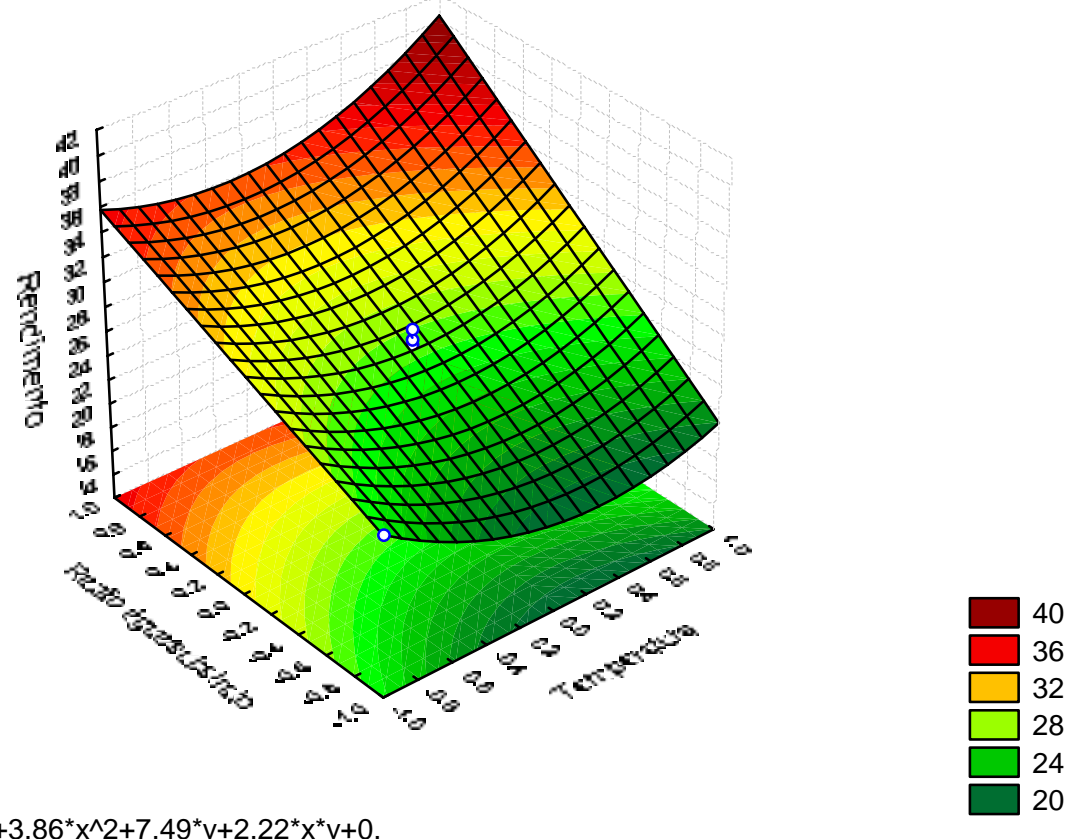

$z=26.70+.1^{*} x+3.86^{*} x^{\wedge} 2+7.49^{*} y+2.22^{*} x^{\star} y+0$. 
Figura 4. Cromatograma do extrato aquoso de inulina de chicória. $\mathrm{T}=90 \mathrm{oC}$ e razão água substrato $=$ $6: 1(\mathrm{p} / \mathrm{p})$

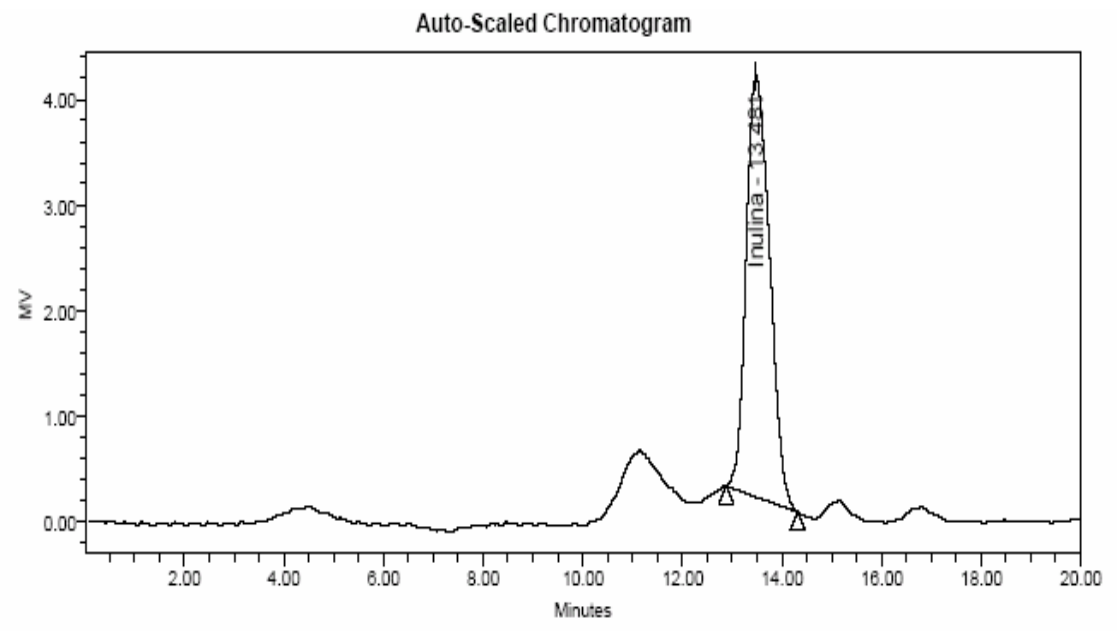

Considerando que a $70^{\circ} \mathrm{C}$ o rendimento alcançado foi cerca de $36 \mathrm{~g}$ de inulina/100 g de amostra, esta temperatura foi fixada para selecionar a razão água/substrato que maximiza o teor de inulina no extrato seco. Como pode ser observado na Figura 5, quando a razão água/substrato diminui o rendimento de extração decresce e a concentração de soluto no extrato aumenta. As duas curvas se interceptam quando se opera entre 25 e $30 \%$ de substrato em relação ao solvente (p/p) na mistura inicial. Neste ponto o rendimento de extrato seco foi superior a $30 \%$ em relação ao peso da raiz desidratada e o teor de soluto na fração aquosa foi da ordem de $18 \%$. O teor de água retido na torta filtrada foi $1,98 \pm 0,33 \mathrm{~g} / \mathrm{g}$ de amostra seca.

O estudo da cinética de transferência de massa mostrou que não houve um aumento significativo na quantidade de soluto extraída após 30 minutos de incubação (Figura 6). A condição operacional que maximizou o teor de inulina no extrato foi: temperatura de $70^{\circ} \mathrm{C}$ e relação solvente/substrato $3: 1$ (p/p). As análises do extrato seco por HPLC indicaram um teor de inulina de $92 \pm 1 \%$ o que corresponde a um rendimento de cerca de $28 \mathrm{~g}$ de inulina/100 g de raiz desidratada (Figura 7). A torta resultante foi submetida a um segundo estágio de extração, nas mesmas condições experimentais, ampliando o rendimento global do processo para $41 \mathrm{~g} \pm 2 \mathrm{~g}$ de inulina por $100 \mathrm{~g}$ de raiz desidratada. 
Figura 5. Rendimento e teor de soluto no extrato para o processo de extração aquosa de inulina de chicória. 1(10\%); 2 (20\%; 3(30\%; 4 (40\%; 5 (50\%)

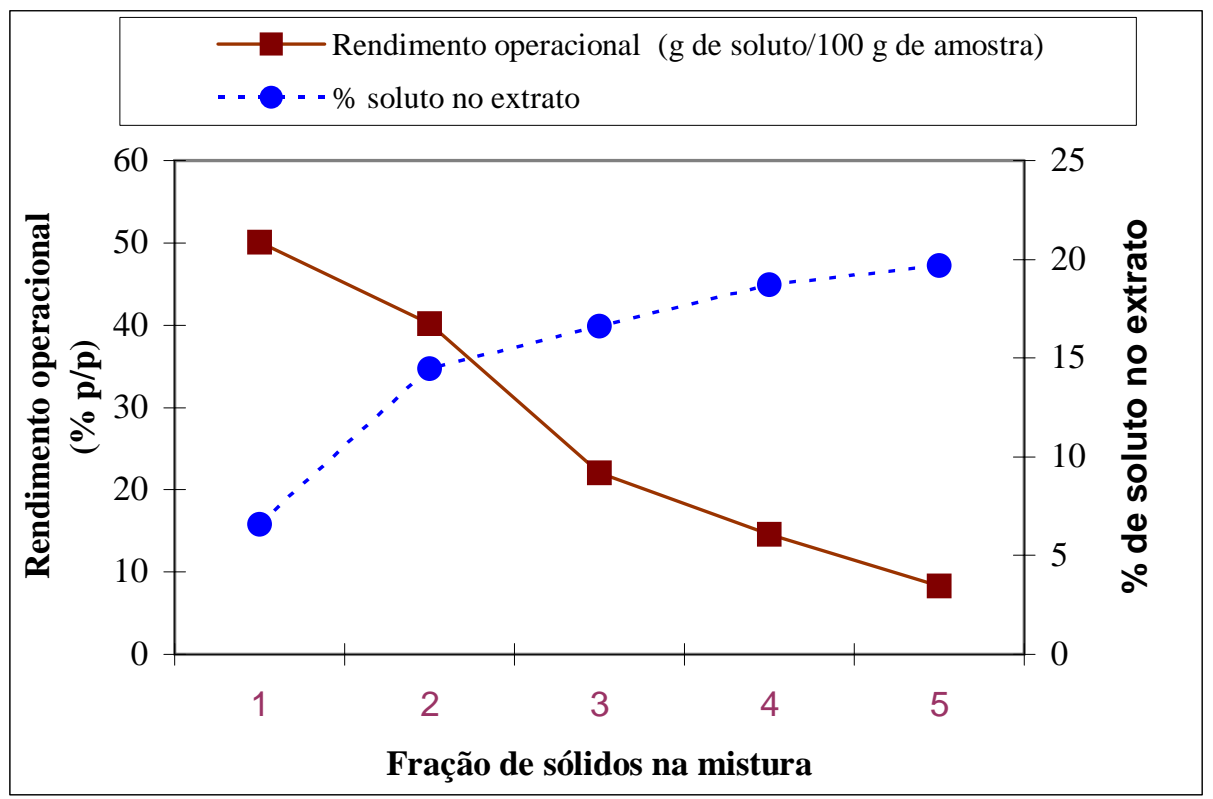

Figura 6. Cinética do processo de extração aquosa de inulina de chicória. T=70oC e razão água/substrato 3:1 (p/p)

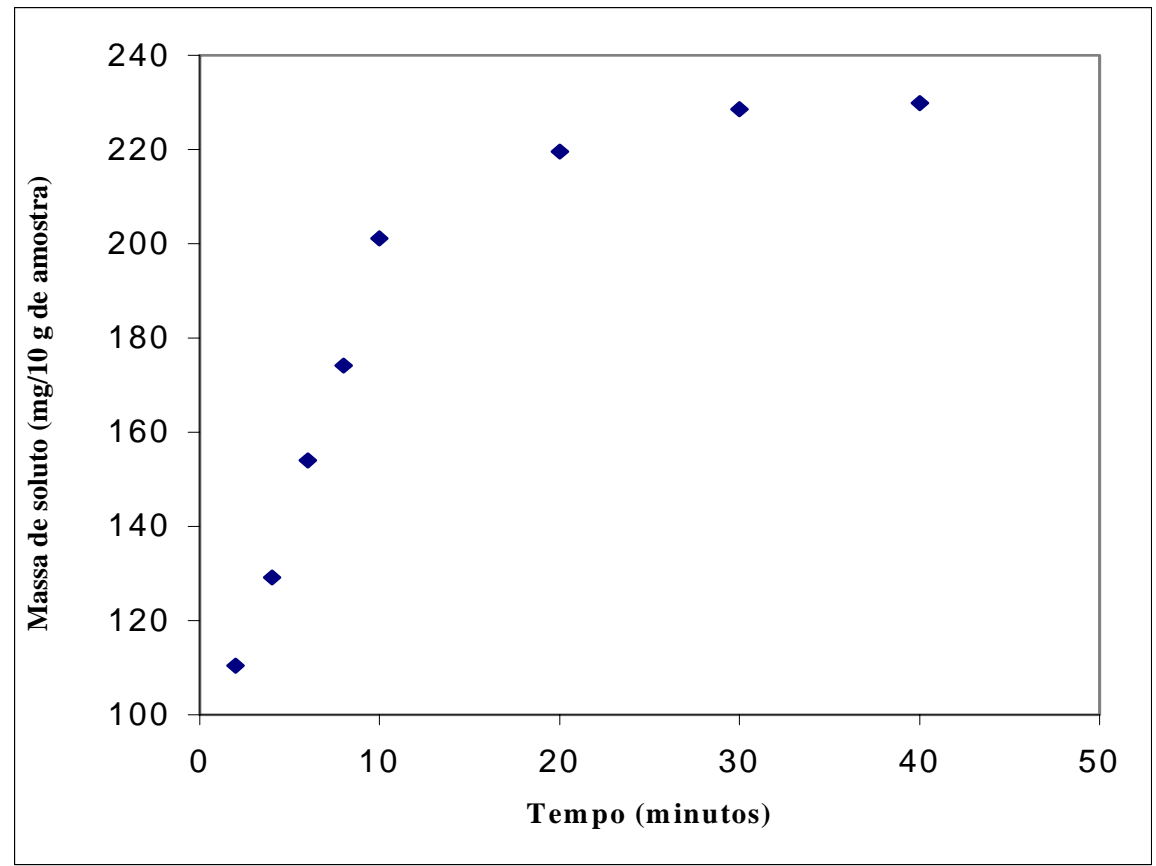


Figura 7. Cromatograma do extrato aquoso de inulina de chicória. $\mathrm{T}=70^{\circ} \mathrm{C}$ e razão água substrato $=$ $3: 1(\mathrm{p} / \mathrm{p})$.

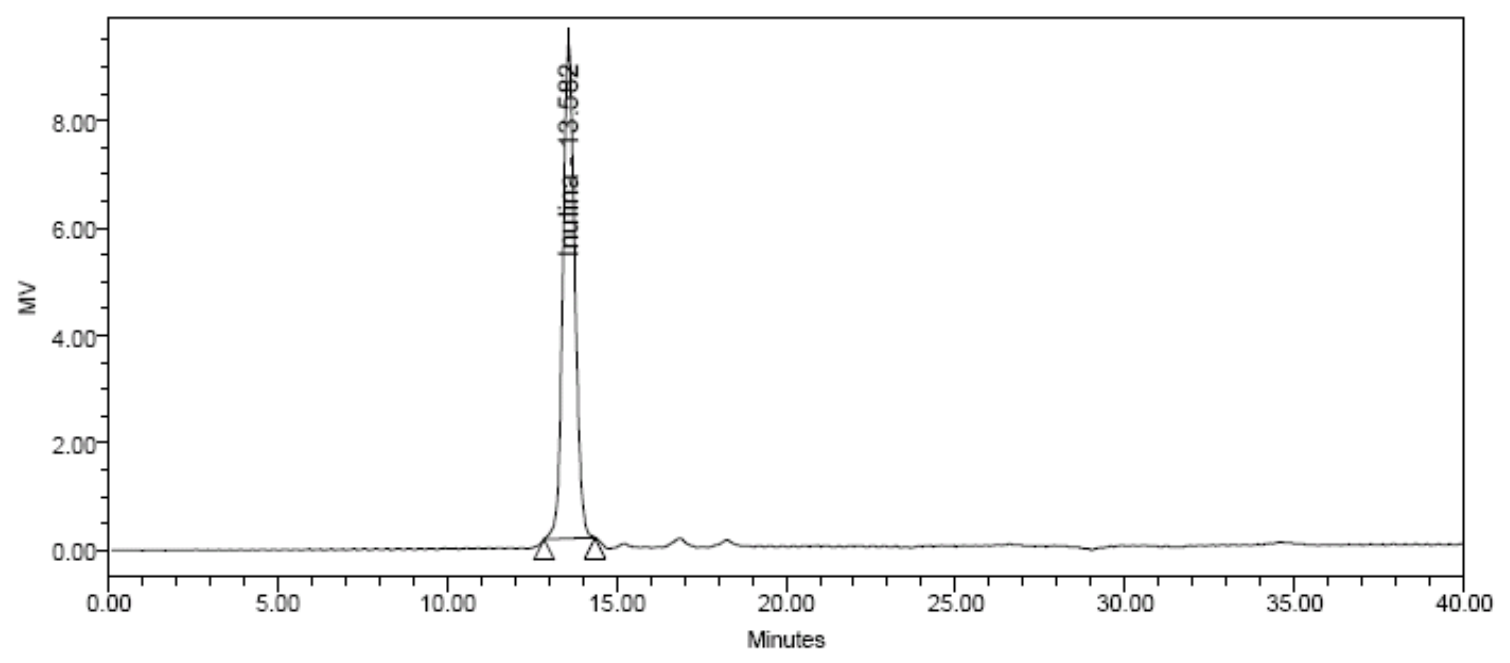

\title{
4. Conclusões
}

O processo de extração aquosa da inulina de chicória, a partir da raiz desidratada, forneceu rendimentos elevados para temperaturas entre 70 e $90^{\circ} \mathrm{C}$ e razão água substrato entre 4:1 e 6:1. As análises do extrato seco por HPLC indicaram um teor de inulina médio de $74 \pm 5 \%$ nas diferentes condições experimentais do planejamento experimental.As condições operacionais selecionadas para maximizar a concentração de inulina no extrato foram: temperatura de $70^{\circ} \mathrm{C}$ e razão água/substrato 3:1. Nestas condições obteve-se um extrato com 18 \% de soluto e um rendimento de extração de cerca de $28 \mathrm{~g}$ de soluto/100 g de amostra. As análises do extrato seco por HPLC indicaram um teor de inulina médio de $92 \pm 1 \%$ confirmando que embora a quantidade de soluto obtida decresça, quando se opera em condições limitantes de solvente, o teor de inulina no extrato aumenta. Isto ocorre, provavelmente, devido à elevada solubilidade da inulina se comparada aos demais componentes da amostra, também solúveis em água.

\begin{abstract}
In this work, the solid-liquid extraction process, using hot water as solvent, was optimized for inulin recovery from dried chicory roots. In the preliminary tests, the extracted soluble solids were analyzed in order to identify the influence of temperature and water/substrate ratio on solute yield. The extraction processes were carried out and optimized according to a central composite design. The response surface methodology was applied to select the relevant parameters. The inulin content in the dry soluble solids was determined by high performance liquid chromatography (HPLC). It could be confirmed that solute yield has a positive correlation with water/substrate ratio $(\mathrm{p}=0.02)$ but the temperature increase in the analyzed range $\left(70\right.$ to $\left.90^{\circ} \mathrm{C}\right)$ was found to be not significant $(p=0.3416)$. The HPLC analysis indicated an inulin content of $74 \pm 5 \%$ in dry basis. The kinetics of mass diffusion, at $70^{\circ} \mathrm{C}$, has indicated a time of 30 minutes to reach the maximum yield. Aiming to optimize both the extracted soluble solids and inulin content in the dry solute, new experiments were carried out at fixed temperature $\left(70^{\circ} \mathrm{C}\right)$ for different substrate/water ratio (10 to $\left.50 \% \mathrm{w} / \mathrm{w}\right)$. For the selected operations parameters, the aqueous solution presented a solute concentration of $18 \%$ and an inulin content of $92 \pm 1 \%$ in dry basis.
\end{abstract}

Key-words: inulin, chicory roots, aqueous extraction 


\section{Referências}

ALZUGARAY, D.; ALZUGARAY, C. Chicória Amarga. Plantas que curam - A natureza a serviço da saúde. n.11, v.40., p.153-154, 1983.

BARROS NETO, B.; Scarminio, I. S.; Bruns, R. E. Planejamento e otimização de experimentos. $2^{\mathrm{a}}$ ed. Campinas: Editora da UNICAMP, 1996, 299p.

BOX, G.E.P.; HUNTER, W.G.; HUNTER, J.S. Statistics for experimenters: an introduction to design, data analysis and model building. $1^{\text {a }}$ ed. New York: John Wiley \& Sons, 1978. 653 p.

COURI, S.; GOMES, F. S.; NOGUEIRA, R. I.; WILBERG, V. C.; CABRAL, L. M. C.; SILVA, V. V. ; ALMEIDA D. L. Determination of inulin content of chicory roots ( Cichorium intybus L.) cultivated organically in three regions of Rio de Janeiro state. In: ENPROMER 2005, Angra dos Reis- RJ, agosto 2005.

FIGUEIRA, G. M. Desenvolvimento agrotecnológico da espécie Cichorium intybus L Campinas, 2000. 68p. Tese (Doutorado em Engenharia Agrícola), Faculdade de Engenharia Agrícola, Universidade Estadual de Campinas, Campinas-SP.

LEITE, J.T.C. Obtenção de extrato de inulina de chicória (Cichorium intybus) por abaixamento de temperatura e secagem por spray dryer. Campinas 2001. Tese (Mestrado em Engenharia Agrícola) Faculdade de Engenharia Agrícola, Universidade Estadual de Campinas, Campinas-SP.

NOGUEIRA, R. I. Processo de obtenção de inulina de chicória (Cichorium intybus) em pó. Campinas, 2002. Tese (Doutorado em Engenharia de Alimentos), Faculdade de Engenharia de Alimentos, Universidade Estadual de Campinas, Campinas-SP.

OLIVEIRA, R. A. de; OLIVEIRA, W. P. de; PARK, K. J. Determinação da difusividade efetiva de raiz de chicória. Engenharia Agrícola, Jaboticabal, n. 1, v. 26., p. 181-189, 2006.

ROBERTFROID, M. Inulin \& Oligofructose: are they functional food ingredients? Ciencias de alimentos: Avanços e Perspectivas, ed. UNICAMP, v.2., p.203-205, 2001.

SILVA, R.F. Use of inulin as a natural texture modifier. Cereal Foods World. St. Paul. n.10, v. 41., p.792-795, 1996.

\section{Agradecimentos.}

A FAPERJ e ao CNPq pelo apoio financeiro.

\section{Dados completos do primeiro autor:}

nome completo: Suely Pereira Freitas (autor para correspondência)

Filiação institucional: Universidade Federal do Rio de Janeiro

Departamento: Departamento de Engenharia Química

Função ou cargo ocupado: professor adjunto II

Endereço completo para correspondência: Escola de Química -UFRJ, Av. Horácio Macedo, 2030, Edifício do Centro de Tecnologia, Bloco E / sala 207

Cidade Universitária - CEP: 21941-909

Telefones para contato: (21) 2562-7634; cel: 94113330

e-mail:freitasp@eq.ufrj.br. 